\title{
Evaluation of Humanistic Ecology in Chinese Tourist Cities: A Case Study of Qingdao
}

\author{
Yan Jiang
}

\author{
Shandong Technology and Business University \\ Email: yuqingcool423@163.com
}

\begin{abstract}
As an effective means of measuring the sustainable and healthy development of cities, eco-health assessment is mainly conducted through evaluation of natural, social and economic indicators. To evaluate the eco-health of tourist cities with humanistic features within the traditional assessment model may affect the soundness and completeness of eco-health assessment system. This study provided a tentative definition of humanistic ecology and attempted to establish a fourdimensional humanistic eco-health assessment system that incorporated humanistic landscape, humanistic environment, humanistic cultivation and humanistic concern with data collected from questionnaires and semi-structured interviews with specialist informants. The establishment of humanistic ecology system will play an important complementary role in refining eco-health assessment system.
\end{abstract}

Keywords: Tourist city, humanistic ecology, evaluation indicators, Qingdao

\section{INTRODUCTION}

With their unique resource advantages in attracting tourists and providing products and services for tourists as their main goals ${ }^{[1]}$, tourist cities are expected to entertain tourists to their hearts' content and make them feel the humanistic concern from the destination cities. Unfortunately, the rapid development of China's tourism industry has given rise to some unpleasant phenomenon. Some key tourist cities, for instance, appeared to take economic development as the first priority and neglect humanistic development ${ }^{[2]}$. Such improper actions as transforming the layout of the original historical buildings to new urban areas, squandering historical and cultural resources to create tourism propaganda gimmicks, infringing on the rights and interests of tourists for economic earnings seem to expand in recent years ${ }^{[3]}$. As is revealed by the developmental trajectories of internationally renowned tourist cities, neglecting the humanistic construction and protection in the process of urban development will directly discredit a city's good image and cause irreversible or permanent destruction to urban culture, which, in turn, impedes the healthy and sustainable social and economic development of tourist cities. In this sense, investigating the structure of humanistic ecology in tourist cities, exploring the connotation of urban humanistic ecology and constructing the evaluation index system of humanistic ecology in tourist cities are of great significance to analyze the connections between humanistic ecology and urban eco-system in tourist cities.

The systematic research on the humanistic system of tourist cities still seems scant. Given the important role that humanistic ecology plays in the development of tourist cities, this study attempts to construct the index system for evaluating tourist city's humanistic ecosystem. To achieve this end, this study is going to choose Qingdao, the best domestic tourist city in China, to make a case study. With the data obtained from in-depth interviews with specialist informants and a large scale questionnaire survey, this study uses the multi-objective linear weighted model to dynamically evaluate the data of Qingdao from 2006 to 2015 for its humanistic ecological health. Meanwhile, this study also makes a comparative study on the correlational relationship between tourism development and humanistic ecological construction in Qingdao before and after the 2008 Olympic Sailing Regatta to verify the significant role of humanistic ecological indicators play in evaluating the ecological construction of tourist cities.

\section{CONSTRUCTION OF HUMANISTIC ECOLOGY INDICATORS SYSTEM}

On the basis of results obtained from questionnaire surveys and in-depth interviews, taking characteristics of 
tourist cities into consideration, following the principles of comprehensiveness, representativeness, comparability and availability of indictors, this indicator system of Qingdao humanistic ecology is constructed from four dimensions, namely, humanistic landscape, humanistic environment, humanistic literacy and humanistic concern.
In order to distinguish the importance of each indicator in the evaluation index system of humanistic ecology, the weight coefficient of each indicator was determined by expert survey and analytic hierarchy process (AHP) method, as shown in Table 1.

Table 1. Indicator system and indicator weight of humanistic ecology in Qingdao

\begin{tabular}{|c|c|c|c|c|}
\hline Component & Category & Indicator & $\begin{array}{l}\text { Nature of } \\
\text { indicator }\end{array}$ & $\begin{array}{l}\text { Weight of } \\
\text { indicator }\end{array}$ \\
\hline \multirow{7}{*}{$\begin{array}{l}\text { Humanistic } \\
\text { landscape }\end{array}$} & & L1 Ornamental index (grade) & + & 0.0486 \\
\hline & Landscape & L2 Diversity index $(H)$ & + & 0.0234 \\
\hline & attributes & L3 Dominance index (D) & - & 0.0193 \\
\hline & & L4 Uniformity index (E) & + & 0.0211 \\
\hline & $\begin{array}{l}\text { Ecological } \\
\text { development and }\end{array}$ & $\begin{array}{l}\text { L5 Proportion of humanistic landscape tourists to } \\
\text { total visitors (\%) }\end{array}$ & + & 0.0336 \\
\hline & protection & L6 Proportion of maintenance cost to total tourism & & 0.0319 \\
\hline & & income (\%) & + & \\
\hline \multirow{11}{*}{$\begin{array}{l}\text { Humanistic } \\
\text { environment }\end{array}$} & & L7 Public health satisfaction (\%) & + & 0.0383 \\
\hline & Living environment & L8 Social security satisfaction (\%) & + & 0.0492 \\
\hline & & L9 Food safety satisfaction (\%) & + & 0.0507 \\
\hline & & L10 Social trust (\%) & + & 0.0363 \\
\hline & Rights and interests & L11 Tourist complaint rate & - & 0.0432 \\
\hline & protection & L12 Tourism industry service satisfaction (\%) & + & 0.0504 \\
\hline & & L13 Business integrity satisfaction (\%) & + & 0.0518 \\
\hline & & L14 Transportation satisfaction (\%) & + & 0.0419 \\
\hline & Public facilities & $\begin{array}{l}\text { L15 Proportion of hotel capability to number of } \\
\text { tourists of that day (\%) }\end{array}$ & + & 0.0397 \\
\hline & & L16 Number of medical and health institutions & + & 0.0326 \\
\hline & & L17 Number of parks & + & 0.0271 \\
\hline \multirow{8}{*}{$\begin{array}{l}\text { Humanistic } \\
\text { literacy }\end{array}$} & & $\begin{array}{l}\text { L18 Percentage of residents with bachelor's degree } \\
\text { or above (\%) }\end{array}$ & + & 0.0313 \\
\hline & Educational level & $\begin{array}{l}\text { L19 Proportion of higher education institutions in the } \\
\text { province (\%) }\end{array}$ & + & 0.0344 \\
\hline & & L20 Proportion of Educational expenditure in GDP & + & 0.0299 \\
\hline & Traditional culture & $\begin{array}{l}\text { L21 Proportion of traditional Chinese courses in the } \\
\text { curriculum of training programs (\%) }\end{array}$ & + & 0.0328 \\
\hline & & L22 Types of folk activities & + & 0.0276 \\
\hline & Public welfare & $\begin{array}{l}\text { L23 Proportion of volunteers in the permanent } \\
\text { population (\%) }\end{array}$ & + & 0.0302 \\
\hline & & L24 Annual per capita donation amount (yuan/) & + & 0.0298 \\
\hline & & L25 Per capita service time of volunteers (hours) & + & 0.0351 \\
\hline \multirow{2}{*}{$\begin{array}{l}\text { Humanistic } \\
\text { concern }\end{array}$} & $\begin{array}{l}\text { Concern for special } \\
\text { groups }\end{array}$ & $\begin{array}{l}\text { L26 Popularization of public facilities for the disabled } \\
\text { (\%) }\end{array}$ & + & 0.0263 \\
\hline & & $\begin{array}{l}\text { L27 Proportion of public places of activity for the } \\
\text { elderly (\%) }\end{array}$ & + & 0.0227 \\
\hline
\end{tabular}




\begin{tabular}{llr}
\hline Spiritual concern & L28 Number of psychological counseling institutions & + \\
& L29 Persons awarded for acting bravely when & 0.0328 \\
& dangerous occasions arise & 0.0280 \\
\hline
\end{tabular}

Note: + for positive (The higher, the better) while - for negative (The lower, the better).

Just like natural landscape, humanistic landscape is also an important tourism resource. It is mainly manifested in the development potential of urban tourism, including the status quo of the attributes of human landscape, its ecological development and protection. Humanistic environment refers to the function of cultural variables inside and outside a certain social system. It is the invisible environment hidden in the social ontology. It is mainly manifested in the living environment of residents in tourist cities, protection of rights and interests and allocation of public facilities. Humanistic literacy is mostly embodied in the outlook on life, world outlook and values. Three indicators are chosen to measure the humanistic literacy of residents in tourist cities: education level, traditional culture and public welfare status. The core of humanistic concern lies in the respect for humanity. The concern for the special groups of residents and tourists and their spiritual state takes a central place in humanistic concern. Among them, care for special groups is measured by the prevalence of public facilities for the disabled and the proportion of public places for the elderly, whereas spiritual concerns are measured by two indicators: the number of psychological counseling institutions and the number of brave and righteous persons who rise up to dangerous occasions.

\section{DATA AND METHODS}

\subsection{Data description}

The data used in the index system are mainly from Qingdao Statistical Yearbook, Shandong Statistical Yearbook from 2007 to 2016 and a survey questionnaire developed for residents and tourists in Qingdao. As for the dimension differences of the indicator system, this study used the range method to standardize the processing.

For positive indicators:

$$
x_{i j}^{\prime}=\left(x_{i j}-\min x_{i j}\right) /\left(\max x_{i j}-\min x_{i j}\right)
$$

For negative indicators:

$$
x_{i j}^{\prime}=\left(\max _{i j}-x_{i j}\right) /\left(\max x_{i j}-\min x_{i j}\right)
$$

In the formula, $x_{i j}^{\prime}, x_{i j}, \max _{i j}, \min x_{i j}$ stands for the standard value, the raw value, the maximum value and the minimum value of the jth indicator of the ith year respectively.

\subsection{Research methods}

In the process of indicator evaluation, the scientific calculation of index weight is an important component of evaluation. In view of the difficulty in quantifying some indicators and the complexity and fuzziness of the evaluation contents in the humanistic ecological evaluation system, this paper chose the analytic hierarchy process (AHP) as a reference to calculate the weight of the indicators. The reasons for choosing this method was out of the following concerns. Firstly, AHP is easy to use and suitable for the combination of qualitative and quantitative analysis. Secondly, it can enhance the accuracy of the decision-making basis. As for the difficulty in overcoming the subjectivity of expert interview results [4], the consistency test was carried out according to the standardized matrix, and the satisfactory consistency was also checked.

When evaluating the importance of various indicators, seven experts were asked to use a 5-point Likert scale to assign values to each indicator and construct a judgment matrix. Then the formula for calculating the weight of indicators is as follows:

$$
\omega_{\mathrm{i}}=\overline{\mathbf{W}}_{\mathrm{i}} / \sum_{\mathrm{i}=1}^{\mathrm{n}} \overline{\mathbf{W}}_{\mathrm{i}}
$$

In the above formula, $\overline{\mathrm{W}}$ represents the nth root of the product of each row of elements.

Given the complexity of the indicator system of humanistic ecology and the experts' potential subjectivity to be involved in the assessing process, it is necessary to test the consistency of judgement matrices and measure the consistency ratio of judgement matrices of different orders.

$$
\begin{gathered}
\mathrm{CR}=\frac{\mathrm{CI}}{\mathrm{RI}} \\
\text { while } \mathrm{CI}=\frac{\lambda_{\max }-\mathbf{n}}{\mathbf{n}-\mathbf{1}}
\end{gathered}
$$

In these two formulae, $\mathbf{C I}$ and $\mathbf{C R}$ stands for consistency index and average random consistency index respectively, $\lambda_{\max }$ and $n$ the maximum eigenvalue of the judgment matrix $A$ and each indicator of the same hierarchy respectively.

When the consistency ratio is smaller than 0.1 , it is considered that the judgment matrix has satisfactory consistency. Otherwise, it is necessary to adjust the judgment matrix to make it reach a satisfactory consistency. 
Because of the complexity of the construction of humanistic ecosystem, a single indicator can just partly reflect the situation of humanistic ecosystem health. By building a multi-objective linear weighted function model, however, the evaluation indicators are synthesized, and the evaluation data and comprehensive indicators of four dimensions humanistic ecology (i.e., humanistic landscape, humanistic environment, humanistic literacy and humanistic concern) in each year are obtained, which can more comprehensively reflect the changes of humanistic ecology before and after Qingdao Olympic Sailing Regatta. The changes of humanistic ecology in each year of Qingdao are analyzed to see the boosting force exerted by humanistic ecology on the development of tourist cities. Its function expression is listed below:

$$
\mathrm{A}=\sum_{i=1}^{m} x_{i} \omega_{i}
$$

In the above formula, A stands for each year's comprehensive index of humanistic ecology; $x_{i}$ and $\omega_{i}$ represent the standardized value of evaluation indicators and the weight of evaluation indicators respectively.

Table 2. Evaluation data of humanistic ecology indicators of Qingdao from 2006 to 2015

\begin{tabular}{lcrrrrrrrrr}
\hline \multicolumn{1}{c}{ Year } & 2006 & 2007 & 2008 & 2009 & 2010 & 2011 & 2012 & 2013 & 2014 & 2015 \\
\hline Humanistic landscape & 0.213 & 0.231 & 0.425 & 0.432 & 0.447 & 0.511 & 0.576 & 0.642 & 0.719 & 0.805 \\
\hline Humanistic environment & 0.322 & 0.346 & 0.441 & 0.482 & 0.523 & 0.569 & 0.615 & 0.672 & 0.723 & 0.811 \\
\hline Humanistic literacy & 0.281 & 0.427 & 0.436 & 0.475 & 0.507 & 0.543 & 0.568 & 0.611 & 0.642 & 0.713 \\
\hline Humanistic concern & 0.235 & 0.352 & 0.411 & 0.456 & 0.482 & 0.513 & 0.547 & 0.571 & 0.619 & 0.672 \\
\hline Composite index & 0.279 & 0.359 & 0.427 & 0.473 & 0.501 & 0.538 & 0.563 & 0.635 & 0.684 & 0.712 \\
\hline
\end{tabular}

The overall evaluation results revealed a consistent rising trend of humanistic ecology in Qingdao. To be specific, within the interacting four dimensions of humanistic landscape, humanistic environment, humanistic literacy and humanistic concern, the value of humanistic ecology of Qingdao has risen steadily from the minimum value of 0.279 in 2006 to the maximum value of 0.712 in 2015 , with an average annual growth rate of $11.31 \%$. The overall index level demonstrated a steady upward trend. Influenced by the 2008 Olympic Sailing Regatta, Qingdao has entered the fast lane of tourism development. The composite indicator of humanistic ecology showed a prominent growth rate, with the investment effect of human landscape construction being particularly noticeable. After the Olympic Sailing Regatta, although the growth rate slows down, the indicators still maintain a steady linear trend of growth. As can be seen from Figure 1, the three dimensions of humanistic landscape, humanistic literacy and humanistic concern for the co-hosting of the Olympic Games in 2008 grew faster than 55\%, and the indicators of human environment grew relatively steadily,

\section{RESULTS AND DISCUSSION}

The purpose of constructing humanistic ecological indicators was to evaluate the health status of tourism city ecology in terms of soft power, and further improve the evaluation indicator system of tourism city eco-health. After checking the reliability and validity of the survey data, the comprehensive indices of four dimensions and indicator system of humanistic landscape, humanistic environment, humanistic literacy and humanistic concern were obtained. Then the indicator system of humanistic ecology in Qingdao from 2006 to 2015 were obtained, as shown in Table 2. Meanwhile, the indicator change curve chart of each year was drawn according to the data (see Figure 1). Considering the current development situation of tourism cities in China and the opinions of the respondents and experts, the weight coefficients of three indicators, namely, food safety satisfaction, service satisfaction and business integrity satisfaction, were adjusted to a higher level. The annual composite index was also obtained for the humanistic ecological evaluation system. averaging about $7 \%$. Not surprisingly, the negative public opinion as a consequence of the notorious "high-priced prawns" in 2015 had negative impact on the development of tourism in Qingdao to some noticeable extent, and its negative impact had significantly reduced the composite index of humanistic ecology in Qingdao. This change confirmed the importance of such humanistic ecology indicators as humanistic environment and humanistic literacy in the process of measuring the ecological health of tourist cities. 


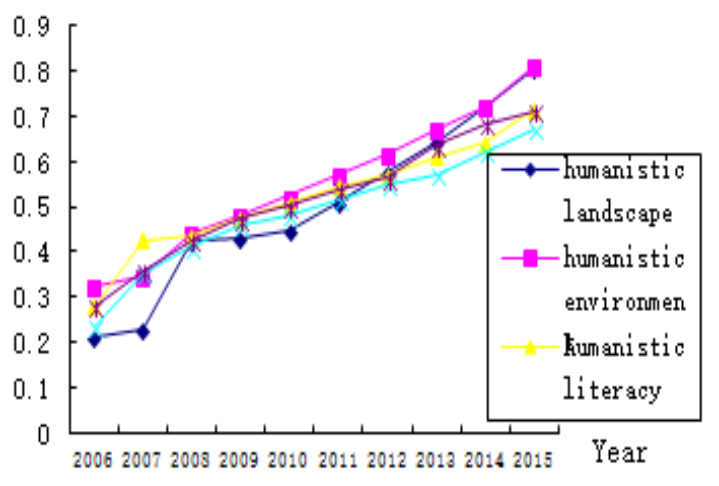

Figure 1 Data of humanistic ecological indices of Qingdao from 2006 to 2015

\section{CONCLUSION}

Based on the unique tourism function of urban ecological development, this study constructed the evaluation index system of humanistic ecology in Qingdao, and evaluated each index of humanistic ecology in Qingdao from 2006 to 2015. Analytic Hierarchy Process (AHP) was introduced in the evaluation process. Consistency analysis, quantitative and qualitative analysis made it easier and more accurate to evaluate and analyze these evaluation indices.

The evaluation results revealed an overall consistency between the data obtained from the humanistic ecological evaluation system and evaluation model with the ecological health situation of Qingdao in the past ten years, which further improves the traditional evaluation system combined by natural, social and economic subsystems. Hopefully, the evaluation index system of humanistic ecology proposed in the present study may help refine strategies for image-building and humanistic orientation promotion of tourist cities.

Inevitably, this study has some limitations. How to refine the connotation of humanistic ecology in a more scientific way, what criteria to include to establish the system, and how to enrich the theory of urban comprehensive ecological evaluation and other relevant issues need further investigation. In addition, the relevant evaluation index system needs to be further refined. How to represent traditional culture and humanistic concern as the soul of the city in the humanistic ecology also deserves further consideration. Lastly, as relevant indexes are difficult to be quantified, their theoretical foundation and evaluation methods also merit further study.

\section{REFERENCES}

[1] J. Bao, S. Gu, Tentative research on RBD of city [J]. Planners, 1998, 14 (4): 59-65.

[2] K. Li, Tourism a big deal in China-ROK ties [R]. 2015-11- 01,http://english.gov.cn/premier/photos/2015/11/01 /content_281475225135009.html

[3] W. Zhang, H. Zhang, Empirical research on bad faith behavior in the tourism market: A case study of travel agencies in Anhui [J]. Tourism Tribune, 2013, 28 (5): 99-108.

[4] N. Zhou, G. He, C. Williams, D. Fridley, ELITE cities: A low-carbon eco-city evaluation tool for China [J]. Ecological Indicators, 2015, 48, 448-456. 